\title{
Comparison Between Tidal Volume and Vital Capacity Breathing Techniques of Preoxygenation in Patients with Ineffective Facemask Seal
}

\section{Farah Arshad, ${ }^{1}$ Hina Nabi, ${ }^{2}$ Fareeda Sohail, ${ }^{3}$ Anum Anwar, ${ }^{4}$ Zulqarnain Butt $^{5}$}

\begin{abstract}
Objective: The purpose of this research was to compare the mean hemoglobin oxygen de-saturation time by using tidal volume breathing technique for three minutes and eight vital capacity breathing technique for preoxygenation in patients with ineffective face mask seal.

Methods: This study included 60 patients with beard, moustache, large nasal bridge, facial anomalies, nasogastric tube and edentulous patients. They were randomized into 2 groups after achieving documented informed consent. Group-A was preoxygenated with TV breathing technique for three minutes at an oxygen flow of 10 litres per minute. Whereas, Group-B was preoxygenated with eight $\mathrm{VC}$ breaths for one minute at an oxygen flow of 10 litres per minute.

Results: The age of the participants varied from 22 years to 65 years with an average of $44.63 \pm 10.03$ years. There were $29(48.3 \%)$ male and $31(51.7 \%)$ female patients in the research group. Both the groups were comparable in respect of mean age $(p=0.839)$ and gender distribution $(p=0.796)$. The mean hemoglobin oxygen desaturation time was considerably longer in VC breathing group ( $6.77 \pm 1.10$ vs. $3.43 \pm .50$ minutes; $\mathrm{p}=0.000$ ) in contrast to TV breathing group regardless of age and gender of patients.

Conclusion: The mean hemoglobin oxygen desaturation time was substancially longer in vital capacity breathing group $(6.77 \pm 1.10$ vs. $3.43 \pm .50$ minutes; $p=0.000)$ in contrast to tidal volume breathing group regardless of patient's age and gender in patients with ineffective face mask seal undergoing elective surgery.

Key Words: Ineffective Face Mask Seal, Preoxygenation Breathing Techniques, Vital Capacity, Tidal Volume, Mean Hemoglobin Oxygen Desaturation Time

How to Cite: Arshad F. Nabi H, Sohail F, Anwar A, Aijaz B, Butt Z. Comparison between tidal volume and vital capacity breathing techniques of preoxygenation in patients with ineffective face mask seal. Esculapio.2020;16(04):46-49.

DOI: https://doi.org/10.51273/esc20.2516410
\end{abstract}

\section{Introduction}

$\mathrm{P}$ reoxygenation with $100 \%$ oxygren is accomplished prior to general anesthesia is induced. The purpose is to enhance oxygen reserves through displacement of nitrogen from functional residual capacity of lungs, thus preventing arterial oxygen desaturation and hypoxemia. Inadequate face mask seal causes a leak that leads to inflow of atmospheric

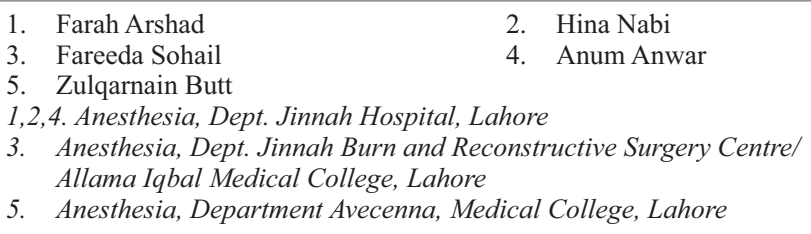

\section{Correspondence:}

Dr Farah Arshad, Department of Anesthesia, Jinnah Hospital, Lahore. Email: faraharshad77@gmail.com

$\begin{array}{ll}\text { Submission Date: } & 05-11-2020 \\ \text { 1st Revision Date: } & 28-11-2020 \\ \text { Acceptance Date: } & 14-12-2020\end{array}$

air into the circuit. The frequently performed methods for preoxygenation are inhalation of $100 \%$ oxygen at normal tidal volume (TV) for three to five minutes or eight full deep vital capacity (VC) breaths in one minute. The available literature declares VC technique to be preferable to TV technique of preoxygenation in terms of mean hemoglobin oxygen desaturation time. However, not enough evidence is published locally. So TV technique for $3 \mathrm{~min}$ will be compared with $8 \mathrm{VC}$ breathing technique for $1 \mathrm{~min}$ at an oxygen flow of upto $10 \mathrm{~L} / \mathrm{min}$ and the measuring parameter for both techniques would be desaturation time.

\section{Methods}

The sample size was approximated as 60 cases by using $95 \%$ confidence level, $80 \%$ power of test with an expected mean time for haemoglobin oxygen desaturation as $3.73 \pm 0.76$ minutes in TV group and 
$5.21 \pm 0.96$ minutes in VC group11. Non-Probability, Purposive Sampling technique was used for selection of 60 patients belonging to either gender, between 18 to 65 years of age, ASA I or II, with Mallampatti class of I or II, scheduled for elective surgery with ineffective face mask seal in patients with beard, moustaches, facial anomalies, nasogastric tube, large nasal bridge and edentulous patients. But the patients who had cardiac disease, pulmonary disease, obesity, smoking history, pregnancy and who denied written informed consent were not incorporated in this research.After endorsement from the local ethical committee all 60 participants were randomly catagorized into two groups by using random number table. Patients in group A were advised to breath normally for three minutes and the patients in group B were directed to take 8 deep breaths for 1 minute. All the patients were given anxiolytics with intravenous nalbuphine $(0.1 \mathrm{mg} / \mathrm{kg})$ and midazolam $(2 \mathrm{mg})$ prior to induction. Monitoring of peripheral oxygen saturation was done by pulse oximetry. After either technique of preoxygenation, induction for general anesthesia was initiated by injecting propofol $(2 \mathrm{mg} / \mathrm{kg})$ and succinylcholine $(1.5 \mathrm{mg} / \mathrm{kg})$ intravenously. Oxygenation via face mask was carried on until spontaneous breathing was ceased within 30 seconds after the injection of succinylcholine. The endotracheal tube was placed in trachea under direct vision and then initial end of the ETT was left open to room air. The time taken by hemoglobin oxygen saturation to fall from $100 \%$ to 95\% was noted and then at this point ETT was attached to ventilator for positive pressure ventilation after the tube position was confirmed. The entire statistical numbers and figures were recorded and scrutinized by using SPSS version 20.

- Numerical variables i.e age and time of desaturation have been presented by mean $\pm \mathrm{SD}$. Independent sample t-test been used to compare mean time of desaturation between the two groups taking $\mathrm{p} \leq 0.05$ as significant.

- Categorical variables i.e. sex has been presented as frequency and percentage.

- Data has been stratified for age and sex to deal with effect modifiers. Post-stratification independent sample t-test has been used taking $\mathrm{p} \leq$ 0.05 as significant.

\section{Results}

The age of the participants varied between 22 to 65 years with an average of $44.63 \pm 10.03$ years. There were twenty nine $(48.3 \%)$ male and thirty one $(51.7 \%)$ female patients in these research groups as demonstrated in Table 1. The two groups were comparable in respect of mean age $(p=0.839)$ and sex distribution $(p=0.796)$, illustrated in Table 2 . The mean hemoglobin oxygen desaturation time was considerably longer in VC breathing group $(6.77 \pm 1.10$ vs $3.43 \pm 0.50$ minutes; $p=0.000)$ as compared to TV breathing group. This difference was appreciated across all age and sex groups as depicted in Table 3.

Table 1: Baseline features of Study Population

\begin{tabular}{|c|c|}
\hline Features & Participants \\
\hline & $n=60$ \\
\hline Age (years) & $\begin{array}{c}44.63 \pm 10.03 \\
(22-65)\end{array}$ \\
\hline \multicolumn{2}{|l|}{ Sex } \\
\hline - Male & $29(48.3 \%)$ \\
\hline - Female & $31(51.7 \%)$ \\
\hline
\end{tabular}

Table 2: Comparison of Baseline Features of Study Groups

\begin{tabular}{cccc}
\hline \multicolumn{1}{c}{ Features } & $\begin{array}{c}\text { TVB } \\
(\mathbf{n}=\mathbf{3 0})\end{array}$ & $\begin{array}{c}\text { VCB } \\
(\mathbf{n = 3 0})\end{array}$ & P value \\
\hline $\begin{array}{l}\text { Age (years) } \\
\text { Sex }\end{array}$ & $44.37 \pm 10.12$ & $44.90 \pm 10.10$ & 0.839 \\
- Male & $14(46.7 \%)$ & $15(50.0 \%)$ & \\
- Female & & & 0.796 \\
& $16(53.3 \%)$ & $15(50.0 \%)$ & \\
\hline
\end{tabular}

Independent sample t-test, Chi-square test, $\mathrm{p}>0.05$

TVB: Tidal Volume Breathing

VCB: Vital Capacity Breathing

Table 3: Comparison of Mean Hemoglobin Oxygen Desaturation Time (minutes) between Study Groups

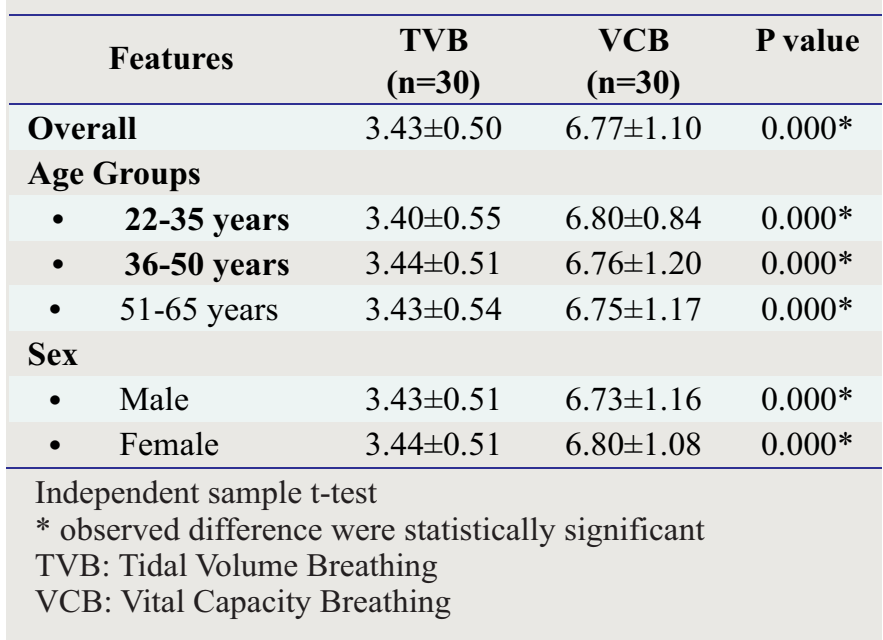




\section{Discussion}

Inadequate face mask seal is the most frequent reason of not attaining a greatest alveolar oxygen concentration during preoxygenation prior to induction of general anesthesia that leads to inflow of atmospheric air into the circuit and decreases the concentration of oxygen present. The frequently performed methods for preoxygenation are inhalation of $100 \%$ oxygen at normal tidal volume (TV) for three to five minutes and eight full deep vital capacity (VC) breaths in one minute. The available literature declares VC technique to be preferable to TV technique of preoxygenation in terms of mean hemoglobin oxygen desaturation time. However, not enough evidence was available in locally published research. The aim of this research was to compare the mean time for hemoglobin oxygen desaturation by using tidal volume (TV) breathing technique for three minutes and 8 vital capacity (VC) breathing technique for pre-oxygenation in patients with ineffective face mask seal. A randomized controlled trial was carried out at Department of Anesthesiology and Intensive Care, Sir Ganga Ram Hospital, Lahore, six months after the acceptance of synopsis from 14th October, 2014 to 13th April, 2015. This study included 60 patients belonging to both genders of age between 18 to 65 years scheduled for elective surgery with inadequate face mask seal randomly divided in group A and group B. Group - A was preoxygenated by tidal volume (TV) breathing technique for three minutes at an oxygen flow of 10 litres per minute. However, Group B was preoxygenated with eight vital capacity (VC) breaths for 1 minute with oxygen flow of 10 litres per minute. A documented informed consent was achieved from every participant. The age of the participants varied between 22 to 65 years with an average of $44.63 \pm 10.03$ years. An equivalent mean age has been stated previously by Rajan et al. in 2015 (47.90 12.17 years),${ }^{102}$ Kundra et al. in 2013 (40.40 \pm 12.40 years), ${ }^{2}$ Ramkumar et al. in 2011 (46.20土 13.20 years), ${ }^{5}$ Kang et al. in 2010 ( $42.20 \pm 2.30$ years), ${ }^{3}$ Delay et al. in $2008(42.90 \pm 11.60 \text { years })^{8}$ and Singh et al. in 2006 (41.40 7.39 years). ${ }^{103}$ However, a much lower mean age of $29 \pm 5$ years has also been noted by Taha et al. in 20094. There were twenty nine (48.3\%) male and thirty one $(51.7 \%)$ female participants in these research groups. A same female preponderance has also been pointed out by Kang et al. in 2010 $(46.67 \% \text { vs } 53.33 \%)^{3}$ and Delay et al. in $2008(21.43$
$\%$ vs $78.57 \%) .{ }^{8}$ However, an equal gender distribution has been noticed by Taha et al. in $2009(50.0 \%$ vs $50.0 \%) .{ }^{4}$ Moreover, a male prevalance was observed by Ramkumar et al. in 2011 (53.33\% vs $46.67 \%){ }^{5}$ The two groups were comparable in respect of mean age $(\mathrm{p}=0.839)$ and sex distribution $(\mathrm{p}=0.796)$. Thus there was no inherent bias among the research groups. The mean hemoglobin oxygen desaturation time was remarkably greater in vital capacity (VC) breathing group $(6.77 \pm 1.10$ vs $3.43 \pm 0.50$ minutes; $p=0.000)$ in comparison with tidal volume (TV) breathing group. This variation was appreciated among all age and sex groups. Our outcome is close to that of Rajan et al. in 2015 (6.87 \pm 1.78 vs $3.47 \pm 0.38$ minutes; $\mathrm{p}<0.001) .{ }^{102}$ A similar considerably longer mean hemo-globin oxygen desaturation time has also been docu-mented in vital capacity (VC) breathing by Singh et al. in $2006(4.70 \pm 0.27 \text { vs } 3.70 \pm 0.44 \text { minutes; } p<0.005)^{103}$ and Baraka et al. in 1999 (5.21 \pm 0.96 vs $3.73 \pm 0.76$ minutes; $p \leq 0.05)^{11}$ in contrast to tidal volume (TV) breathing technique. This research is the initial and earliest of its kind in local population and has noted that vital capacity (VC) breathing technique of preoxygenation is preferable to tidal volume (TV) breathing in respect of considerably longer mean hemoglobin oxygen desaturation time $(6.77 \pm 1.10 \mathrm{vs}$ $3.43 \pm 0.50$ minutes; $p=0.000$ ) regardless of patient's age and gender in patients with inadequate face mask seal scheduled for elective surgery. The findings of this study thus recommend and encourage the use of Vital Capacity breathing technique for preoxygenation in patients with ineffective face mask seal going through elective surgery as it provides remarkably longer mean hemoglobin oxygen desaturation time deferring the occurence of arterial oxygen desaturation and hypoxemia during the apneic period after the general anesthesia is induced.

\section{Conclusion}

The mean hemoglobin oxygen desaturation time was considerably longer in vital capacity (VC) breathing group ( $6.77 \pm 1.10$ vs $3.43 \pm 0.50$ minutes; $\mathrm{p}=0.000)$ in comparison to tidal volume (TV) breathing group regardless of patient's age and gender in patients with ineffective face mask seal going through elective surgery.

\section{Conflict of Interest: None}




\section{References}

1. Lavanya K,Chandra Sekhar T,Padmaja R.A randomized control study comparing the efficacy of 2 techniques of preoxygenation-tidal volume breathing for one min and 8 deep breaths in one minute.Indian Journal of Clinical Anaesthesia 2019;6(1):71-76

2. Patel PK,Kandi S,Soren D,Nayak S.Comparison of two methods of preoxygenation in elderly patients undergoing surgery under general anesthesia.JMCR 2020;v8i1.118.

3. Khandrani J, Modak A, Pachpande B, Walsinge G, Ghosh A. Study of effects ofvarying durations of preoxygenation. Int J Anesthesiol 2008;20(1).

4. Kundra P, Stephen S, Vinayagam S. Techniques of preoxygenation in patients with ineffective facemask seal Indian J Anaesth 2013:57:175-9.

5. Kang H, Park HJ, Baek SK, Choi J, Park SJ. Effect of preoxygenation with the three minutes tidal volume breathing technique in the elderly. Korean J Anesthesiol 2010;58(4):369-73.

6. Taha SK, El-Khatib MF, Siddik-Sayyid SM, Abdallah FW, Dagher CM, Chehade JM, et al. Preoxygenation by 8 deep breaths in 60 seconds using the Mapleson A (Magill), the circle system, or the Mapleson D system. J Clin Anesth 2009;21(8):574-8.

7. Ramkumar V, Umesh G, Philip F. A Preoxygenation with 20 degrees head up tilt provides longer duration of non-hypoxic apnea than conventional preoxygenation in non -obese healthy adults. J Anesth 2011; 25(2):189-94.

8. Thomas MC, Waberski BH, Jonathan C. Extending the Preoxygenation period from 4 to 8 mins in critically ill patients undergoing emergency intubation. Official Journal of the Society of Critical Care Medicine: Lippincott Williams \& Wilkins. 2009;37(1):6871.

9. Solis A, Baillard C. [Effectiveness of preoxygenation using the head-up position and noninvasive ventilation to reduce hypoxaemia during intubation]. Ann Fr Anesth Reanim 2008;27(6):490-4.

10. Delay JM, Sebbane M, Jung B, Nocca D, Verzilli D, Pouzeratte $Y$, et al. The effectiveness of noninvasive positive pressure ventilation to enhance preoxygenation in morbidly obese patients: a randomized controlled study. Anesth Analg 2008;107(5):170713.

11. Taha S, El-Khatib M, Siddik-Sayyid S, Dagher C, Chehade JM, Baraka A. Preoxygenation with the Mapleson D system requires higher oxygen flows than Mapleson A or circle systems. Can J Anaesth 2007;54(2):141-5.

12. Nimmagadda U, Salem MR, Joseph NJ, Miko I. Efficacy of preoxygenation using tidal volume and deep breathing techniques with and without prior maximal exhalation. Can J Anaesth 2007;54(6):44852.

13. Baraka AS, Taha SK, Aouad MT, El-Khatib MF, Kawkabani NI. Preoxygenation: comparison of maximal breathing and tidal volume breathing techniques. Anesthesiology 1999;91(3):612-6.

14. Eriksson LI. The effects of residual neuromuscular blockade and volatile anesthetics on the control of ventilation. Anesth Analg 2004;89:243-51.

15. Baraka A. Safe reversal (2) atropine-neostigmine mixture: An electrocardiographic study. Br J Anaesth 2008;40:30-6.

16. Szreter T. [Preoxygenation--safety of induction]. Anestezjol Intens Ter 2008;40:188-91.

17. Pehbock D, Wenzel V, Voelckel W, Jonsson K, Herff $\mathrm{H}$, Mittlböck M, et al. Effects of preoxygenation on desaturation time during hemorrhagic shock in pigs. Anesthesiology 2010;113:593-9.

18. Rajan S, Mohan P, Paul J, Cherian A. Comparison of margin of safety following two different techniques of preoxygenation. J Anaesthesiol Clin Pharmacol 2015;31:165-8.

19. Singh B, Afzal L, Kaur B, Osahan NK. Comparison of pre-oxygenation by maximal breathing and tidal volume breathing techniques. Indian J Anaesth 2006;50:209-13.

\section{Authors Contribution}

AF: Concept, Conduct of study, Manuscript preparation, editing, Literature review

NH: Manuscript Preparation, Proof Reading, Critical Review

SF: Statistical Analysis of Data

AA, BZ: Data Collection 